\title{
Servicescape, Intercustomer Support, and Their Relations to Consumer Well-Being: An Abstract
}

\author{
Cindy Yunhsin, Lanlung Chiang, Hinyung Wu, and Yu-Ting Huang
}

\begin{abstract}
This study adopts transformative service research (TSR) to enhance the predictive strength of servicescape framework. In particular, this study argues that intercustomer social support, as one of the dimensions of servicescape, has transformational potential to enhance customer perception of servicescape, which in turn, influences customer value co-creation behavior and subjective well-being throughout their experience in a community-based servicescape. Data was analyzed from a total number of 309 valid survey responses, sampling on face-to-face interviews which were carried out in a community-based servicescape, Tamsui, Taiwan. The results showed intercustomer social support has the greatest influence on the customer place attachment in comparison with perceived physical stimuli and community partners' commitment. Given that TSR is still in its infancy, this study contributes to the literature by echoing TSR assertions that service firms possess the transformative strength to enhance customer well-being. This study suggests that firms may promote social support between customers during their consumption in the service environment. In this way, both customer well-being and firms' sustainability can be enhanced.
\end{abstract}

C. Yunhsin $(\bowtie) \bullet$ L. Chiang $\bullet$ H. Wu $\bullet$ Y.-T. Huang

Yuan Ze University, Taoyuan, Taiwan

e-mail: cindy.chou@saturn.yzu.edu.tw; lukech@saturn.yzu.edu.tw; wuhinyung@yahoo.com;

hyttina719@gmail.com 